\title{
The Relationship between High-Tech Product Exports, R\&D Expenditures and Patent Applications: Dynamic Panel Data Analysis for Selected Countries
}

\author{
Mine Yaşar ${ }^{a}$ \\ a Independent Researcher, Turkey, mine-demircelik@hotmail.com, https://orcid.org/0000-0002-1974-4240
}

\section{ARTICLE INFO}

\section{Research Article}

2020, Vol.2(4), 557-571

e-ISSN 2667-5927

Article History:

Received: 08.09.2020

Revised: 23.09.2020

Accepted: 10.10 .2020

Available Online: 23.10 .2020

JEL Code: F10, F13, F14

Keywords: high-tech product export, R\&D expenditures, patent applications, system GMM approach
The Relationship between High-Tech Product Exports, R\&D Expenditures and Patent Applications: Dynamic Panel Data Analysis for Selected Countries

\section{Abstract}

In this study, the effect of R\&D expenditures and number of patent applications on high technology product exports was examined. The analysis was made with data from 52 countries for the period 2007-2018. The lagged value of the share of high-tech exports in total exports which is the dependent variable was also included in the model as an independent variable and the system GMM approach was preferred. In addition, savings, openness ratio and the share of foreign direct investment in GDP, which are other determinants of high technology product exports in the literature, are included in the model as the control variable. According to the findings obtained from the analysis; If the share of R\&D expenditures in GDP increases by $1 \%$, the share of high technology product exports in total exports increases by $0.12 \%$. The $1 \%$ increase in the total of local and foreign patent applications increased the share of high technology product exports in total exports by $0.01 \%$. It is concluded that the lagged value of the share of high technology exports in total exports, which are added to the model as an independent variable, is also an important explanatory.

Yüksek Teknolojili Ürün Ihracatı ile Ar-Ge Harcamaları ve Patent Başvuruları Arasındaki ilişki: Seçilmiş Ülkeler için Dinamik Panel Veri Analizi

$\ddot{Z z}$

Bu çalışmada, Ar-Ge harcamalarının ve patent başvuru sayısının yüksek teknolojili ürün ihracatına olan etkisi incelenmiştir. Analiz, 2007-2018 dönemi için 52 ülke verisiyle yapılmıştır. Bağımlı değişken olan yüksek teknolojili ürün ihracatının toplam ihracat içerisindeki payının gecikmeli değeri de modele bağımsız değişken olarak dâhil edilmiş ve sistem GMM yaklaşımı tercih edilmiştir. Ayrıca literatürde, yüksek teknolojili ürün ihracatının diğer belirleyicileri olarak kabul edilen tasarruflar, dışa açıklık oranı ve doğrudan yabancı yatırımların GSYiH içerisindeki payı, modele kontrol değişken olarak dâhil edilmiştir. Analizden elde edilen bulgularına göre; Ar-Ge harcamalarının GSYiH içerisindeki payının \%1 artması durumunda, yüksek teknolojili ürün ihracatının toplam ihracat içerisindeki payı \% 0.12 artmaktadır. Yerel ve yabancı patent başvuruları toplamında meydana gelen \%1'lik artış ise, yüksek teknolojili ürün ihracatının toplam ihracat içerisindeki payını \% 0.01 arttırmıştır. Modele bağımsız değişken olarak eklenen yüksek teknolojili ihracatın toplam ihracat içerisindeki payının gecikmeli değerinin de önemli bir açıklayıcı olduğu sonucuna ulaşılmıştır.

To cite this document: Yaşar, M. (2020). The Relationship Between High-Tech Product Exports, R\&D Expenditures and Patent Applications: Dynamic Panel Data Analysis for Selected Countries, BILTURK, The Journal of Economics and Related Studies, 2(4), 557-571. doi: 10.47103/bilturk.791786
Anahtar Kelimeler: yüksek teknolojili ürün ihracatı, Ar-Ge harcamaları, patent başvuruları, sistem GMM yaklaşımı 
Yaşar, M. (2020). The Relationship Between High-Tech Product Exports, R\&D Expenditures and Patent Applications: Dynamic Panel Data Analysis for Selected Countries, BILTURK, The Journal of Economics and Related Studies, 2(4), 557-571. doi: 10.47103/bilturk.791786

\section{Giriş}

Ülkelerin teknolojik gelişme seviyeleri, ülkeler arasındaki rekabeti etkileyen en önemli faktörlerden birisi haline gelmiştir. Ülkelerin teknoloji üretebilme yetenekleri ve ürettikleri teknolojiyi ihraç edebilme kapasiteleri, söz konusu ülkenin ekonomik büyümesine de ciddi ölçüde katkı sağlamaktadır. Bu sebeplerden ötürü, ülkeler, uluslararası rekabet üstünlüğü sağlayabilmek amacıyla teknolojik gelişme seviyelerini ve ihracatlarında yüksek teknolojili ürünlerinin oranını arttırmayı hedeflemektedirler (Şeker, 2019: 379). Ülkelerarası gelişmişlik farklııklarına baktığımızda, kendi teknolojisini üretebilen ve üretim miktarlarını arttırabilen ülkelerin, ekonomik büyüme ve kalkınmalarını planladıkları şekilde gerçekleştirebildikleri görülmektedir (Kızılkaya vd., 2017: 64).

Ülkeler için teknolojik düzeyi arttırmak ulusal bir takım çabalar ve teknoloji transferi olmak üzere iki yöntemle mümkündür. Ulusal çabalarla teknoloji seviyesini arttırmayı hedefleyen ülkelerin, söz konusu ülkenin bilimsel altyapısının geliştirilmesine ağırlık vermeleri gerekmektedir. Teknoloji transferi yolunu tercih eden ülkeler için ise, dış ticaret, doğrudan yabancı yatırımlar, lisans ve patent haklarının devri gibi yöntemleri izlemektedirler. Her iki yolun tercih edilmesi durumunda da, bu sürecin başarılı olması için, ülkedeki teknolojik yeteneğin belirli bir düzeyde olması, temel koşuldur (Demirtaş, Aktop, 2018: 71).

Araştırma geliştirme faaliyetleri ve yenilik, yüksek teknolojili ürün ihracatının temelini oluşturmaktadır. Yüksek teknolojili ürünler, yüksek katma değer yaratabildiklerinden dolayı, söz konusu ülkenin ihracat gelirleri olumlu yönde etkilenmekte ve böylece ekonomik büyümenin gerçekleşmesini sağlamaktadır. Bir ülkenin yüksek teknolojili ürün ihracatı ne kadar yüksekse, o ülkenin refah seviyesi, rekabet edebilme gücü ve uluslararası alanda söz sahibi olma gücü de artar (Çapik, Kaygısız, 2018: 303). Bir ülke, yüksek teknolojili ürün ihracatında ne kadar başarılı ise, o ülkedeki sanayilerin rekabet gücü de o kadar yüksek kabul edilmektedir. Yüksek teknolojili ürün piyasasındaki büyüme, diğer ürün piyasalarından daha hızlı gerçekleşmektedir. Bu durumun sebebi, taleplerin gelir esnekliği, ürün yeniliği ve verimlilik artışının yüksek olmasından kaynaklanmaktadır. Dolayısıyla, bir ülke, yüksek teknolojili ürünlerinde rekabetçi bir duruma gelebilirse, söz konusu ülkenin sürdürülebilir bir ihracat büyümesini yakalaması daha kolaydır (Kabaklarlı ve Konya, 2019: 4419).

Çalışmanın bundan sonraki bölümlerinde, teorik çerçeve başığı altında, teknolojiyi temel alan modellere değinilmiş, Ar-Ge ile teknoloji ve büyüme ilişkisi, yüksek teknolojili ürün ihracatının belirleyicileri, yüksek teknolojili ürün ihracatının ülke ekonomisine katkılarından bahsedilmiştir. Çalışmanın bir sonraki bölümünde Literatür başlığı altında, literatürde yer alan belli başlı çalışmalar incelenmiş ve çalışmaların bulguları paylaşılmıştır. Sonraki bölümde çalışmada kullanılan veri seti, model ve yöntem açıklanmıştır. Çalışmanın sonuç bölümünde ise, analizden elde edilen bulgular değerlendirilmiş ve politika önerileri sunulmuştur. 
Yaşar, M. (2020). The Relationship Between High-Tech Product Exports, R\&D Expenditures and Patent Applications: Dynamic Panel Data Analysis for Selected Countries, BILTURK, The Journal of Economics and Related Studies, 2(4), 557-571. doi: 10.47103/bilturk.791786

\section{Teorik Çerçeve}

Rekabet gücünün temel itici gücü olarak inovasyon anlayışının temelleri, pazar dinamiklerini yaratıcı bir yıkım süreci olarak tanımlayan Schumpeter'in çalışmalarına dayanmaktadır. Daha sonra bu kavramı bir "yaratıcı birikim" süreci olarak adlandırarak daha da geliştirmiştir. Bu sonraki modelde, firmalar teknolojik yetenekleri biriktirme ve yenilik üretme konusunda farklı kapasitelere sahiptir. Birikmiş teknolojik yetkinlikler, firma yenilikçiliğinin ve rekabet gücünün temel belirleyicileri ve itici güçleridir (Dobrinsky, 2008: 53). Schumpeter'in, ortaya koyduğu büyüme modelinde, firmalar ve tüketiciler yenilik talebinde bulunur. Bu yenilik talebi, üretim ve tüketimi teşvik eder ve eskiler zaman içinde yok olur (Göçer, 2013: 218).

Neo-Klasik Büyüme Teorisinin öncüsü olan Solow ve Swan, teknolojik değişimi sabit kabul etmiştir. Daha sonra ortaya konan modeller (Arrow (1962), Uzawa (1965), Rebelo (1991)), teknolojik değişimi içermeyen modellerdir. 1980'lerin sonlarına doğru Romer (1986) ve Lucas (1988)'ın katkıları ile ortaya atılan ve gelişen içsel büyüme teorileri, mülkiyet haklarının korunması, finansal piyasaların düzenlenmesi, altyapı yatırımları, maliye politikası gibi unsurların uzun dönem büyüme oranına ciddi etkisi olacağını savunmuşlardır (Ünlükaplan, 2009: 237238).

Romer (1986, 1990), Grossman ve Helpman (1991a, 1991b), Aghion ve Howit (1992) tarafından geliştirilen Ar-Ge Modellerinin temelleri Schumpeter (1947)'in görüşlerine dayanmaktadır. Bu modellerde ara mal, nihai mal ve Ar-Ge sektörleri önemli bir konuma sahiptir. Sektörler arası etkileşim söz konusudur. Ar-Ge sektörü, yenilikçi fikir ve buluşlarını beşeri sermaye aracılığıyla üretmekte ve bu ürünleri ara mal sektörüne satmaktadır. Ara mal sektörü, üretilen fikir ve buluşların patentini alıp nihai mal sektörüne satmaktadır. Bu döngüde Ar-Ge sektörü oldukça önemli bir yere sahiptir (Özçelik, Aslan, Özbek, 2018: 58). Bu ekonomistlere göre, yeni teknolojilerin yaratılmasına harcanan kaynakların (Ar-Ge harcamalarının) düzeyinde meydana gelen sürekli bir artış, ekonomik büyümede de sürekli bir artış meydana getirecektir (Göçer, 2013: 218).

Yüksek teknolojili ürün ihracatı yapan ülkeler, tasarrufların etkin yatırıma dönmesi, nitelikli eğitim sonucu nitelikli işgücünün istihdam edilmesi, Ar-ge faaliyetleri sonucu elde edilen yenilikler gibi çeşitli faktörlerin birbiriyle etkileşimi sonucu, yüksek teknolojili ürün ihracatı yapma kapasitesine ulaşabilmektedirler. Bu anlamda, Ar-ge harcamaları, Patent Başvuru Sayısı, Sabit Sermaye Yatırımı, Dışa Açıklık Oranı, Doğrudan Yabancı Yatırımlar, Nitelikli İstihdam Sayısı ve Tasarruf Oranı gibi değişkenler, literatürde yüksek teknolojili ürün ihracatının önemli belirleyicileri olarak kabul görmektedir (Güneş ve Akın, 2019: 13). 
Yaşar, M. (2020). The Relationship Between High-Tech Product Exports, R\&D Expenditures and Patent Applications: Dynamic Panel Data Analysis for Selected Countries, BILTURK, The Journal of Economics and Related Studies, 2(4), 557-571. doi: 10.47103/bilturk.791786

Araştırma geliştirme, toplum bilgisi ve kültürü de içerisine alan sahip olduğu bilgi birikimini arttırmak ve var olan bilgiyle yeni uygulamalar oluşturmak için yapılan yaratıcı ve sistematik çalışmaların bütünü olarak tanımlanabilir. Yeni, yaratıcı, sistematik, belirsiz, aktarılabilir olma özellikleri, bir uğraşın Ar-Ge olabilmesi için temel kriterler olarak gösterilmektedir (Seçilmiş vd., 2019: 30).

Ülkelerin sahip oldukları doğal kaynaklar, nitelikli işgücü, teknoloji gibi unsurlar, ülkeler arasındaki gelir düzeyi, büyüme oranı gibi iktisadi farklılıkların temelini oluşturmaktadır. Ülkelerin bu farklılıkları kapatabilmek için eğitime daha fazla kaynak aktarmak teknoloji transferi içeren doğrudan yabancı yatırımları ve Ar-Ge yatırımlarını teşvik etmek gibi faaliyetlerini arttırmak durumunda oldukları görülmektedir. Yapılan son çalışmalara bakıldığında, bu faktörlerden en önemlisinin Ar-Ge harcamaları olduğu görülmektedir. Ar-Ge harcamaları, dış ticaret yoluyla yüksek teknolojili ürün ihracatını arttırmakta ve böylece o ülkenin ekonomik büyümesine katkı sağlamaktadır (Kılıç vd., 2014: 116). Ekonomik büyüme ve uluslararası rekabette ciddi oranda olumlu etki yaratmasının anlaşılmasıyla beraber ülkelerin Ar-Ge'ye verdikleri önem de giderek artmaktadır (Altıntaş ve Mercan, 2015: 347).

Yüksek teknolojili ürün ihracatının belirleyicilerinden biri olarak kabul gören patentler, inovasyon süreci sonunda elde edilen en önemli çıktı olarak kabul edilmektedir. Yüksek teknolojili ürün üreticisi firmalar açısından önemli avantajları bulunmaktadır. Patentler, söz konusu firma tarafından üretilen ürün ya da üretim yöntemini, rakip firmalar tarafından piyasaya sürülmesi muhtemel sahtelerinden korumaya yardımcı olurlar (Akyol ve Demez, 2020: 56). Patent sayıları ayrıca, söz konusu ülkenin araştırma geliştirme sisteminin etkinliği hakkında bilgi sunmaktadır. Yerli patent sayıları, ülkelerin gerçekleştirdiği icat sayılarını, dolayısıyla araştırma geliştirme çıktılarını ifade ederken, aynı zamanda söz konusu ülkenin yenilikçi potansiyeli hakkında da bilgi sahibi olunmasını sağlamaktadır (Şeker, 2019: 379).

Yüksek teknolojili ürün ihracatının bir diğer belirleyicisi olan doğrudan yabancı yatırımlar ise, bir ülkenin ekonomik büyüme ve kalkınmasında önemli bir faktör olarak kabul edilmektedir. Günümüzde, teknoloji transferinin büyük çoğunluğu çok uluslu şirketler tarafından yapılan yatırımlarla gerçekleşmektedir (Yaşar, 2014: 207). Doğrudan yabancı yatırımlar vasıtasıyla ev sahibi ülke tek başına elde edemeyeceği teknoloji transferini gerçekleştirmekte ve bu teknolojiyi kullanarak yüksek teknolojili ürün ihracatını arttırma hedefini gerçekleştirebilmektelerdir (Kızılkaya vd. 2018: 67).

Literatürde, yüksek teknolojili ürün ihracatının bir diğer belirleyicisi olarak kabul gören dışa açıklık oranı da ise, transit ticaret yolu ile yüksek teknolojili ürün ihracat performansını arttırmakta ve ülke içinde yüksek teknolojili üretim için kullanılacak bazı girdilerin yurtdışından temin edilmesine imkan sağlamaktadır (Güneş ve Akın, 2019: 14). 
Yaşar, M. (2020). The Relationship Between High-Tech Product Exports, R\&D Expenditures and Patent Applications: Dynamic Panel Data Analysis for Selected Countries, BILTURK, The Journal of Economics and Related Studies, 2(4), 557-571. doi: 10.47103/bilturk.791786

Bir ülkenin gelişmişlik düzeyinin önemli bir göstergesi olan yüksek teknolojili ürün ihracatı yoğunluğu, aynı zamanda ülkelerin rekabet edebilirlik gücü ile de yakından ilişkilidir. Ülkelerin yeni teknoloji üretebilmeleri ve ürettikleri teknolojiyi ihraç edebilmeleri bu açıdan oldukça önemlidir. Böylece toplumsal refah ve yaşam kalitesini de arttırıcı etkiye sahip olacaktır (Oğuz, Sökmen, 2020: 212).

\section{Literatür}

Landesmann ve Pfaffermayr (1997), çalışmalarında G-7 ülkeleri için 1967-1987 dönemini kapsayan veri setini kullanmışlardır. Elde edilen bulgulara göre, Ar-Ge faaliyetlerinin, ihracat üzerinde genellikle pozitif yönde etkisi olduğu sonucuna ulaşılmaktadır. ABD, İngiltere ve Japonya gibi ülkelerde, Ar-Ge, ihracatı olumlu yönde etkilemiştir. Ancak, Almanya ve bazı durumlarda Fransa için Ar-Ge'nin ihracat üzerinde görece daha düşük bir etkisinin olduğu hatta bazen de bu etkinin negatife döndüğü belirtilmiştir. Benzer sonuçlara ulaşan Zhang (2007), bir ülkenin 1985-1998 yıllarındaki karmaşık ihracatının büyüklüğünü açıklayan faktörleri incelemeyi amaçladığı çalışmasında, 87 ülke verilerini kullanmıştır. Çalışmanın sonucunda bir ülke ihracatının, söz konusu ülkedeki endüstriyel teknoloji kapasitesiyle yakından ilişkili olduğu bulgusuna ulaşılmıştır.

Braunerhjelm ve Thulin (2008), artan Ar-Ge harcamalarının ve Pazar büyüklüğünün karşılaştırmalı üstünlüğün dağılımını nasıl etkilediğini inceledikleri çalışmada, 19 OECD ülkesini ve 1981-1999 dönemi kapsayan veri seti kullanmışlardır. Panel Veri Analizi kullandıkları çalışmanın sonucunda, Ar-Ge harcamalarında \%1'lik bir artışın yüksek teknoloji ihracatında \%3'lük bir artışa işaret ettiği yönündedir. Pazar büyüklüğünün etkisini olmadığı sonucunu ortaya koyan çalışmada ayrıca, kurumsal faktörlerin karşılaştırmalı üstünlüğün dinamiklerini etkilediği sonucuna ulaşılmıştır.

Özer ve Çiftçi (2009), çalışmalarında Ar-Ge harcamaları, araştırmacı sayıları ve patent sayılarının GSYiH üzerindeki etkisini incelemişlerdir. OECD ülkeleri için panel veri tekniği kullanılarak yapılan analizlerde, Ar-Ge harcamaları, araştırmacı sayıları ve patent sayılarının GSYIH üzerinde pozitif ve yüksek oranlı bir etkiye sahip olduğuna yönelik bulgular elde edilmiştir. Bojnec ve Ferto (2011), araştırma ve geliştirmenin imalat sanayi ticareti üzerindeki etkilerini incelemeyi amaçladıkları çalışmalarında, OECD ülkeleri için 1995-2003 dönemi verilerini kullanmışlardır. Çalışma, Ar-Ge'nin ticaret akışları üzerindeki doğrusal olmayan etkisine, Ar-Ge'nin, ekonomik gelişmişlik seviyesi ve uzaklığın imalat ticareti üzerindeki rolünün aşılmasında yardımcı olup olmayacağına odaklanmıştır ve Gravity model kullanılmıştır. Araştırma sonuçları, Ar-Ge'nin ihracatçı ülkeler için imalat ticareti ile pozitif yönde ilişkili olduğunu, ithalatçı ülkeler için ise sonuçların karışık olduğunu göstermektedir. Tahminler ise, Ar-Ge'nin mesafenin imalat 
Yaşar, M. (2020). The Relationship Between High-Tech Product Exports, R\&D Expenditures and Patent Applications: Dynamic Panel Data Analysis for Selected Countries, BILTURK, The Journal of Economics and Related Studies, 2(4), 557-571. doi: 10.47103/bilturk.791786

ihracatı üzerindeki etkilerinin aşılmasına katkıda bulunabileceğini ve ithalatta uzmanlaşmayı güçlendirebileceğini göstermektedir.

Halpern ve Muraközy (2011), 2004-2006 dönemi verilerini kullanarak firma bazında araştırma yapmışlardır. Ar-Ge harcamalarının ihracatı pozitif yönde etkilediği sonucuna ulaşmışlardır. Ayrıca yabancı firmaların, benzer yerli firmalara kıyasla yenilik yapma olasılığının daha yüksek olduğunu, ancak Ar-Ge miktarının, yabancı firmaların yenilikçi çıktılarının daha zayıf bir etkileyicisi olduğunu belirtmişlerdir.

Gülmez ve Yardımcıoğlu (2012), 1990-2010 dönemi verilerini kullanarak 21 OECD ülkeleri için Ar-Ge harcamaları ve ekonomik büyüme arasındaki uzun dönem ilişkinin varlığını araştırmışlardır. Çalışmalardan elde edilen bulgular Ar-Ge harcamalarındaki \%1'lik bir artışın ekonomik büyüme üzerinde uzun dönemde yaklaşık olarak \%0,77'lik bir artış meydana getirdiği yönündedir. Yıldırım ve Kesikoğlu (2012), 25 alt sektörü kapsayan veri seti kullanarak, 1996-2008 dönemi için Ar-Ge harcamaları ve ihracat arasındaki nedensellik ilişkilerini incelemişlerdir. GMM sistem tahmini ve Wald testi yöntemiyle yaptıkları nedensellik analizi sonuçlarına göre, Ar-Ge harcamalarından ihracata doğru tek yönlü nedensellik ilişkisi tespit etmişlerdir.

Göçer (2013), çalışmasında Ar-Ge harcamalarının yüksek teknolojili ürün ihracatı, bilgi iletişim teknolojileri ihracatı, toplam ihracat ve ekonomik büyüme üzerindeki etkilerini 1996-2012 dönem verilerini kullanarak 11 Asya ülkesi için panel veri analizi yöntemiyle analiz etmiştir. Çalışmanın sonucuna, Ar-Ge harcamalarındaki \%1'lik artışın yüksek teknolojili ürün ihracatını \%6,5; bilgi-iletişim teknolojileri ihracatını \%0,6 ve ekonomik büyümeyi \%0,43 oranında arttırdığı tespit edilmiştir. Dam ve Bulut (2015) çalışmasında, Ar-Ge yatırımlarının dış ticaret performansına etkisini 21 OECD ülkesi için, 1996-2012 dönemi verileri kullanarak panel eşbütünleşme ve panel nedensellik testleri kullanarak analiz etmiştir. Çalışmanın sonucunda, ihracattan Ar-Ge'ye \%1 anlamlılık düzeyinde nedensellik ilişkisi tespit edilmiş olup, bunun artan gelirinin, firmaların Ar-Ge'ye daha fazla kaynak ayırabilmesinden kaynaklandığını öne sürmüştür. Ar-Ge'den ihracata ise \%10'luk anlamlılık düzeyinde nedensellik ilişkisi tespit edilmiştir.

Çetin (2016), Ar-Ge harcamalarının yüksek teknolojili ürün ihracatına etkisini incelediği çalışmasında, 7 sanayileşen ülkenin 1996-2013 dönemi verilerini analiz etmiştir. Yüksek teknoloji ürünü olarak kabul edilen 5 sektörün verileri kullanılan çalışmanın sonuçlarına göre, Ar-Ge harcamaları yüksek teknoloji ürün ihracatına pozitif ve anlamlı bir etki göstermektedir. Özkan ve Yılmaz (2017), çalışmalarında AB üye ülkeleri ve Türkiye için 1996-2015 dönem verilerini incelemişler, panel veri analiz yöntemini kullandıkları çalışmalarının sonucunda Ar-Ge harcamalarının Yüksek Teknolojili Ürün İhracatı ve GSYiH'yı pozitif yönde etkilediği bulgusuna ulaşmışlardır. Ar-Ge harcamalarında meydana gelen \%1'lik bir artışın yüksek teknoloji ihracatında \%3.5'luk, GSYiH'da ise \%1.38'lik bir artış meydana getirdiği sonucuna ulaşılmıştır. 
Yaşar, M. (2020). The Relationship Between High-Tech Product Exports, R\&D Expenditures and Patent Applications: Dynamic Panel Data Analysis for Selected Countries, BILTURK, The Journal of Economics and Related Studies, 2(4), 557-571. doi: 10.47103/bilturk.791786

Acaravcı vd. (2019), 1990-2014 dönemini kapsayan yıllık verileri kullanarak Ar-Ge harcamalarının kişi başı reel ihracatına etkilerini araştırdıkları çalışmalarında, ArGe harcamalarındaki ve ticaret ortaklarının ortalama kişi başına reel gelirindeki bir artışın, Türkiye kişi başı reel ihracatını pozitif yönde etkiledikleri sonucuna ulaşmışlardır.

Akyol ve Demez (2020), çalışmalarında yeni endüstrileşen ülkeler grubu özelinde inovasyonun yüksek teknoloji ürün ihracatı üzerindeki etkisini analiz etmişlerdir. Çalışma sonucunda, 1996-2015 yılları arası dönemi kapsayan ve söz konusu gruba dahil 8 ülkeyi içine alan inovasyon faaliyetlerinin, yüksek teknoloji ürün ihracatı üzerinde olumlu bir etki oluşturduğu gözlemlenmiştir. Ayrıca toplam patent başvurularında meydana gelen \%1'lik artışın, yüksek teknolojili ürün ihracatında \% 0.21 oranında artış sağladığı sonucuna ulaşmışlardır.

\section{Model, Veri Seti ve Yöntem}

\subsection{Model ve Veri Seti}

Bu çalışmanın amacı, Ar-Ge harcamalarının ve patent başvuru sayısının yüksek teknolojili ürün ihracatına olan etkisini incelemektir. Çalışma, 2007-2018 dönemi için 52 ülke1 verisiyle yapılmış olup, kullanılan verilerin tümü Dünya Bankası'ndan alınmıştır. Kullanılan her bir verinin doğal logaritması alınmıştır. Bağımlı değişken olan yüksek teknolojili ürün ihracatının toplam ihracat içerisindeki payının gecikmeli değeri de modele dahil edilmiş ve sistem GMM yaklaşımı tercih edilmiştir. Dinamik panel yaklaşımı çerçevesinde Ar-Ge harcamalarının ve patent başvuru sayısının yüksek teknolojili ürün ihracatına olan etkisini analiz edebilmek için aşağıdaki gibi bir regresyon modeli kullanılmıştır:

$$
\begin{aligned}
& \text { Lnyti }_{i, t}=\beta_{0}+\beta_{1} \text { Lnyti }_{i, t-1}+\beta_{2} \text { Lnar-ge } \\
& +\beta_{5} \text { Lpatent }_{i, t}+\beta_{6} \text { Lndyy }_{i, t}+u_{i, t}
\end{aligned}
$$

Burada $t$, zaman aralığını (2000-2017), i, birim sayısını (57), $\beta_{1}, \beta_{2}, \beta_{3}, \beta_{4}, \beta_{5}$ parametre katsayılarını, $\beta_{0}$, sabiti ve u hata terimini temsil etmektedir. Modeldeki bağımlı değişken olan "Lnyti", yüksek teknolojili ürün ihracatının toplam ihracata oranını ifade etmektedir. "Lnytii,t-1" bağımlı değişken olan yüksek teknolojili ürün ihracatının toplam ihracata oranının gecikmeli değerini ifade etmektedir ve modele bağımsız değişken olarak dahil edilmiştir. Bağımsız değişkenler olan "Lnar-

\footnotetext{
${ }^{1}$ Örnekleme dahil olan ülkeler: Arjantin, Ermenistan, Avusturya, Azerbaycan, Belçika, Bulgaristan, Kanada, Şili, Çin, Kolombiya, Kosta Rika, Hırvatistan, Kıbrıs, Çekya, Danimarka, El Salvador, Estonya, Finlandiya, Fransa, Almanya, Yunanistan, Hong Kong, Macaristan, İzlanda, İrlanda, İsrail, İtalya, Japonya, Güney Kore, Letonya, Litvanya, Lüksemburg, Malta, Hollanda, Norveç, Polonya, Portekiz, Romanya, Rusya, Sırbistan, Singapur, Slovakya, Slovenya, Güney Afrika, İspanya, İsveç, İsviçre, Tayland, Türkiye, İngiltere, ABD, Uruguay'dır.
} 
Yaşar, M. (2020). The Relationship Between High-Tech Product Exports, R\&D Expenditures and Patent Applications: Dynamic Panel Data Analysis for Selected Countries, BILTURK, The Journal of Economics and Related Studies, 2(4), 557-571. doi: 10.47103/bilturk.791786

ge", Ar-Ge harcamalarının GSYiH içerisindeki payını ve "Lnpatent", yerel ve yabancı toplam patent başvuru sayısını ifade etmektedir.

Tablo 1: Değişkenlerin Tanımlanması

\begin{tabular}{|c|c|c|c|}
\hline Değişken & Veri Tanımlaması & Kaynak & Dünya Bankası Veri Kodu \\
\hline Lnyti & $\begin{array}{l}\text { Yüksek teknolojili ürün ihracatının } \\
\text { toplam ihracata oranı }\end{array}$ & Dünya Bankası & TX.VAL.TECH.MF.ZS \\
\hline Lnar-ge & $\begin{array}{l}\text { Ar-Ge harcamalarının GSYIH } \\
\text { içerisindeki payı }\end{array}$ & Dünya Bankası & GB.XPD.RSDV.GD.ZS \\
\hline Lntasarruf & Gayrisafi yurtiçi tasarruflar & Dünya Bankası & NY.GDS.TOTL.CN \\
\hline Lnaçıklık & Dışa açıklık oranı & Dünya Bankası & NE.TRD.GNFS.ZS \\
\hline Lnpatent & $\begin{array}{l}\text { Yerel ve yabancı yerleşiklerin } \\
\text { toplam patent başvuru sayısı }\end{array}$ & Dünya Bankası & IP.PAT.NRES \\
\hline Lndyy & $\begin{array}{l}\text { Doğrudan yabancı yatırımların } \\
\text { GSYiH içerisindeki payı }\end{array}$ & Dünya Bankası & BX.KLT.DINV.WD.GD.ZS \\
\hline
\end{tabular}

Ayrıca literatürde, yüksek teknolojili ürün ihracatının diğer belirleyicileri olan "Lnasarruf", gayrisafi yurtiçi tasarrufları (cari yerel para birimiyle), "Lnaçıklık", dışa açıklık oranı ve "Lndyy", doğrudan yabancı yatırımların GSYï içerisindeki payı, modele kontrol değişken olarak dâhil edilmiştir.

\subsection{Yöntem}

Bu çalışmada Dinamik Panel Veri yöntemi tercih edilmiştir. Dinamik Panel veri yöntemi, Statik Panel yöntemine kıyasla bazı avantajlar sunmaktadır. Modeldeki değişkenlerin içsellik problemini ortadan kaldırmak için gecikmeli değerler olarak da bilinen bir takım araç değişken kullanılmasını mümkün kılmaktadır (Akalın ve Uzgören, 2019:210). Bunun yanı sıra, içsel değişkenlere sahip modellerin tahmin edilmesiyle birlikte, daha karmaşık modeller oluşturabilmek de mümkündür. Ancak, dinamik panel veri yönteminin bazı zayıf tarafları da mevcuttur. İlk olarak tahminciler, tutarsız sonuçlar verebilir ve rapor edilen değerler, örneklemin karakteristik özelliklerine bağı olabilmektedir. Kullanılan gecikmeli değerler, serilerin korelasyon problemlerini çözmeye yetmeyebilir. Bunlara ek olarak, yalnızca zayıf araçların mevcut olduğu durumda bazı içsel regresörlere uygun araçlar bulmak karmaşıklaşmaktadır. Bu yöntemin bir diğer kısıtı, analizde uzun zaman serisi $(\mathrm{T})$ ve az sayıda birimlerin (N) kullanılması modelin aşırı tanımlanması sonucunu doğurabilmektedir (Ruíz-Porras 2012). Arellano ve Bover (1995) ve Blundell ve Bond (1998) tarafından geliştirilen GMM-sistem yaklaşımı, modeldeki içsellik problemini çözmekte başarılı ve $N>T$ özelliği taşıyan modellere uygulanabilen bir yaklaşımdır. Bir araç değişken metodu olma özelliği taşıyan bu yaklaşımda, içsellik problemi taşıdığı düşünülen değişkenler yerine, benzer özellikler taşıdığı düşünülen araç değişkenlerin üretilip regresyon modeline dahil 
Yaşar, M. (2020). The Relationship Between High-Tech Product Exports, R\&D Expenditures and Patent Applications: Dynamic Panel Data Analysis for Selected Countries, BILTURK, The Journal of Economics and Related Studies, 2(4), 557-571. doi: 10.47103/bilturk.791786

edilmesi üzerine kurulmuştur (Yıldırım, Kesikoğlu, 2012: 171). Arellano Bover sistem GMM yaklaşımında 1. fark ve düzey eşitliklerinin yer aldığı sistemin moment kısıtları kullanılmaktadır. Han, Phillips ve Sul'a (2014) göre; Sistem GMM tahmincilerinin fark işlemlerine dayandığından dolayı model tahminleri, değişkenlerin birim kök içerip içermemesinden etkilenmemektedir. Sistem GMM tahmincisi, değişkenlerin durağan olmadığı durumlarda dahi etkin tahminciler olabilmektedirler.

$\mathrm{Bu}$ çalışmada kullanılan veri seti $N>T^{\prime}$ dir ve bağımlı değişkenin gecikmeli değerlerinin regresörler arasında yer aldığı modellere uygun olduğundan ve dolayısıyla modeldeki içsellik problemini çözmede başarılı olduğundan dolayı GMM Sistem Yaklaşımı uygulanılmıştır.

GMM tahmincisi kullanılmasının, araçların çoğalması ve hata terimlerinin seri otokorelasyonu olmak üzere 2 ana sorunu vardır: Kullanılan model, geniş bir zaman dilimi (büyük T) ve az sayıda birim (küçük N) içeriyorsa bu iki sorun daha da büyüyecektir. Araçların çoğalması, daha yüksek bir araç seviyesinin varlığına işaret etmektedir. Bu da fark ve seviyelerde araç değişken üretilmesinin bir sonucu olarak (farklarda sadece gecikmeli araç değişkenleri kullanılan Arellano ve Bond tahmincisi hariç) modelin aşırı tanımlanmasıyla sonuçlanacaktır. Araç sayısının yeterli olup olmadığını ve aşırı tanımlama olmadığının araştırılması için iki test mevcuttur. Bunlar Sargan Testi ve Hansen testidir. Dinamik Panel Veri Yöntemi, hata terimlerinin seri korelasyonunun olmamasını gerektirir. Hata terimlerinin seri otokorelasyonunun bu durumu, Arellano ve Bond testi kullanılarak önlenebilir, tahmin homoskedastik bir ağırlık matrisi dikkate alınarak yapıldığında Sargan testi yeterlidir (Labra ve Torrecillas, 2018: 41).

\section{Ampirik Bulgular}

\subsection{Sistem GMM Tahmin Sonuçları}

GMM tahmincilerinin tutarlılığına ilişkin üç temel test uygulanmıştır: Bunlardan ilki; modelde kullanılan değişkenlerin bir bütün olarak anlamlı olup olmadığını gösteren Wald testidir. Tablo 2'de görüldüğü üzere, Wald Chi2 testi, modelin bütün olarak anlamlı olduğunu göstermektedir. Modelde bir bütün olarak bağımsız değişkenlerin yüksek teknolojili ürün ihracatı üzerinde istatistiki olarak anlamlı bir etkisinin olduğu ortaya çıkmaktadır. İkinci olarak, modelde kullanılan araç değişkenlerin geçerli olup olmadığını gösteren Sargan testi yapılmıştır. Sargan testi şu şekilde yorumlanmaktadır. Elde edilen olasılık değeri, 0,05'e eşit veya daha yüksek ise, tahminde kullanılan araçlar geçerlidir ve aşırı tanımlama yoktur (Labra ve Torrecillas, 2018: 48). Tablo 2'de görüldüğü gibi Sargan testi sonuçlarına göre; modelde kullanılan araç değişkenler geçerlidir. Dinamik panel yöntemlerinin etkinliği için, hata teriminde korelasyon olmaması koşuluyla mümkündür 
Yaşar, M. (2020). The Relationship Between High-Tech Product Exports, R\&D Expenditures and Patent Applications: Dynamic Panel Data Analysis for Selected Countries, BILTURK, The Journal of Economics and Related Studies, 2(4), 557-571. doi: 10.47103/bilturk.791786

(Cameron ve Trivedi, 2009). Bunu test etmek için Arellano ve Bond testi kullanılmaktadır. Tablo 2'de görüldüğü gibi Arellano ve Bond testi AR(2) değeri, hata terimleri arasında seri otokorelasyonun olmadığını göstermektedir.

Tablo 2: Sistem GMM Tahmin Sonuçları

\begin{tabular}{lcc}
\hline \hline \multicolumn{1}{c}{ Değişkenler } & Katsayılar & Olasılık Değeri \\
\hline \hline Lnytit-1 & $0.7096(10.60)^{* * *}$ & 0.000 \\
Lnarge & $0.1241(3.78)^{* * *}$ & 0.000 \\
Lnpatent & $0.0100(1.66)^{*}$ & 0.097 \\
Lntasarruf & $0.0117(2.12)^{* *}$ & 0.034 \\
Lnaçıklık & $0.1032(2.81)^{* * *}$ & 0.005 \\
Lndyy & $0.0190(2.68)^{* * *}$ & 0.007 \\
\hline \hline Tanı Testleri & Test İstatistikleri & 0.000 \\
\hline \hline Wald Test & $\chi^{2}(18)=3883.61$ & 0.278 \\
Sargan Testi & $\chi^{2}(6)=7.49$ & 0.011 \\
AR (1) & -2.53 & 0.656 \\
AR (2) & -0.45 & \\
Grup Sayısı & 52 & \\
Araç Sayısı & 25 & \\
\hline \hline
\end{tabular}

Not: $* * *, * *, *$ sırasıyla $\% 1, \% 5$ ve $\% 10$ düzeyinde istatistiki anlamlılığı göstermektedir. Tabloda sadeliğin korunması adına, zaman kuklalarına ait katsayılara burada yer verilmemiştir.

Modelden elde edilen tahmin sonuçlarına göre, bağımsız değişkenler olan yüksek teknolojili ürün ihracatının toplam ihracata oranının gecikmeli değeri ve Ar-Ge harcamalarııı GSYiH içerisindeki payı, istatistiksel olarak \% 1 düzeyinde anlamlıdır. Yerel ve yabancı toplam patent başvuru sayısı ise, istatistiksel olarak \% 10 düzeyinde anlamlıdır. Yüksek teknolojili ürün ihracatının literatürde kabul edilen diğer belirleyicileri olan ve modele kontrol değişkenler olarak dahil edilen, tasarruflar, dışa açıkık oranı ve doğrudan yabancı yatıımların GSYiH içerisindeki payının da sırasıyla, istatistiksel olarak \% $5, \% 1$ ve \%1 düzeyinde anlamlı olduğu görülmektedir.

Elde edilen katsayılar incelendiğinde, literatürde incelenen çalışmaları destekler nitelikte olup bağımsız değişkenler olan yüksek teknolojili ürün ihracatının toplam ihracata oranının gecikmeli değerinin ve Ar-Ge harcamalarıın GSYiH içerisindeki payının, yerel ve yabancı toplam patent başvuru sayısını ve kontrol değişkenler olan, gayrisafi yurtiçi tasarruflarının, dışa açıklık oranının ve doğrudan yabancı yatırımların GSYiH içerisindeki payının da aynı şekilde yüksek teknolojili ürün ihracatını pozitif olarak etkilediği görülmektedir. 
Yaşar, M. (2020). The Relationship Between High-Tech Product Exports, R\&D Expenditures and Patent Applications: Dynamic Panel Data Analysis for Selected Countries, BILTURK, The Journal of Economics and Related Studies, 2(4), 557-571. doi: 10.47103/bilturk.791786

\section{Sonuç ve Öneriler}

Ülkelerin sahip oldukları teknolojinin ülke ekonomisine sağladığı faydalar göz önüne alındığında, teknolojiye atfedilen önem de kuşkusuz giderek artmaktadır. Bir ülkenin teknolojik gelişmişlik seviyesi arttıkça, o ülkeye uluslararası rekabet üstünlüğü sağlamakta, büyüme ve ihracatını olumlu etkilemekte ve ülkelerin kalkınmaları planlı bir şekilde gerçekleşebilmektedir.

Literatürdeki çalışmalar incelendiğinde, Ar-ge harcamaları, Patent Başvuru Sayısı, Sabit Sermaye Yatırımı, Dışa Açıklık Oranı, Doğrudan Yabancı Yatııımlar, Nitelikli İstihdam Sayısı ve Tasarruf Oranı gibi değişkenlerin yüksek teknolojili ürün ihracatının önemli belirleyicileri olarak karşımıza çıktığı görülmektedir. Bu çalışmada, Ar-Ge harcamaları ve patent başvuru sayısının yüksek teknolojili ürün ihracatı üzerindeki etkileri, 52 seçilmiş ülke için 2007-2018 dönemi verileri kullanılarak dinamik panel veri yöntemi olan sistem GMM tekniği ile analiz edilmiştir.

Analiz sonuçları, Ar-Ge harcamalarının ve Patent başvurularının, yüksek teknolojili ürün ihracatına pozitif ve istatistiki olarak anlamlı bir etkisinin olduğunu ortaya koymaktadır. Ayrıca literatürde, yüksek teknolojili ürün ihracatının diğer belirleyicileri olan, tasarruflar, dışa açıklık oranı ve doğrudan yabancı yatırımlar modele kontrol değişken olarak eklenmiştir. Sonuçlar incelendiğinde, Ar-Ge harcamalarının GSYiH içerisindeki payının \%1 artması durumunda, yüksek teknolojili ürün ihracatının toplam ihracat içerisindeki payı \% 0.12 artmaktadır. Yerel ve yabancı patent başvuruları toplamında meydana gelen $\% 1^{\prime}$ lik artış ise, yüksek teknolojili ürün ihracatının toplam ihracat içerisindeki payını \% 0.01 arttırmıştır. Modele bağımsız değişken olarak eklenen yüksek teknolojili ihracatın toplam ihracat içerisindeki payının gecikmeli değerinin de, yüksek teknolojili ürün ihracatının toplam ihracat içerisindeki payını etkileyen en önemli değişken olduğu görülmektedir.

Son olarak modele eklenen kontrol değişkenlerin de literatüre uyumlu olarak yüksek teknolojili ürün ihracatını pozitif yönde etkilediği görülmektedir. Tasarruflarda, dışa açıklık oranında ve doğrudan yabancı yatırım girişlerinde meydana gelen \%1'lik bir artış, yüksek teknolojili ürün ihracatının toplam ihracat içerisindeki payını sırasıyla \% 0.01, \% 0.10, \% 0.01 arttırmaktadır.

Çalışmanın sonuçlarını bütün olarak değerlendirildiğinde, genel olarak literatürdeki bazı diğer çalışmalarla (Yıldııım ve Kesikoğlu (2012), Göçer (2013), Dam ve Bulut (2015), Özer ve Çiftçi (2009), Halpern ve Muraközy (2011),Çetin (2016), Akyol ve Demez (2020)) uyumlu olduğu görülmektedir. Ülkelerin sürdürülebilir bir büyüme oranını yakalamaları, daha yüksek bir ihracat geliri elde etmeleri ve uluslararası rekabet gücünü arttırabilmeleri için, belirli bir teknolojik 
Yaşar, M. (2020). The Relationship Between High-Tech Product Exports, R\&D Expenditures and Patent Applications: Dynamic Panel Data Analysis for Selected Countries, BILTURK, The Journal of Economics and Related Studies, 2(4), 557-571. doi: 10.47103/bilturk.791786

gelişmişlik seviyesine ulaşmaları ve yüksek teknolojili ürün ihracatının toplam ihracat içerisindeki payını arttırmaları gerektiği önemli bir gerçektir. Yapılan çalışmalardan elde edilen bulgulara bakıldığında, teknoloji üretebilmenin ve ihraç edebilmenin temelinde Ar-Ge harcamalarının oldukça önemli bir rolü olduğu görülmektedir. Ar-Ge harcamaları için milli gelirden ayrılan payın arttırılması da bu nedenle önemlidir. Milli gelirden Ar-Ge harcamalarına ayırılan pay arttıkça, katma değeri yüksek ürünlerin üretimi ve yüksek teknolojili ürün ihracatı da hızlanacaktır. Bu bağlamda hem kamu sektörünün hem de özel sektörün üniversitelerle işbirliği içerisinde olması, Ar-Ge faaliyetlerinin kesintisiz sürdürülebilmesine destek olması, teşvik paketleri oluşturulması oldukça önemli görülmektedir. Politika yapıcıların Ar-Ge harcamalarına vereceği destek, patent başvuru sayısı ve nitelikli istihdam sayısını olumlu olarak etkileyecektir. Ayrıca politika yapıcılar tarafından daha fazla teknoloji üreten ve bunu diğer sektörlere yayabilen endüstrilerdeki doğrudan yabancı yatırım türlerini ülkeye çekebilecek teşvik politikaları geliştirilmelidir. Diğer taraftan küresel pazarlara entegrasyon olarak görebileceğimiz dışa açıklık oranının arttırılmasında daha fazla çaba gösterilmesinin de, ülkelerin tek başına elde edemeyecekleri bazı teknolojilerin transferini kolaylaştırmada önemli katkısı olacaktır, bu yolla da yüksek teknolojili ürün ihracatının toplam ihracat içerisindeki payı artacaktır. 
Yaşar, M. (2020). The Relationship Between High-Tech Product Exports, R\&D Expenditures and Patent Applications: Dynamic Panel Data Analysis for Selected Countries, BILTURK, The Journal of Economics and Related Studies, 2(4), 557-571. doi: 10.47103/bilturk.791786

\section{Kaynaklar}

Acaravcı, A., Akalin, G., \& Erdoğan, S. (2019). Araştırma-Geliştirme Harcamalarının Türkiye İhracatına Etkileri. Hacettepe Üniversitesi Iktisadi ve Idari Bilimler Fakültesi Dergisi, 37(1), 1-16.

Akalin, G., \& Uzgören, E. Kurumsal Kalitenin Gelir Dağılımı Üzerindeki Etkisi: Gelişmiş ve Gelişmekte Olan Ülkeler için Ampirik Bir Analiz. Eskişehir Osmangazi Üniversitesi İktisadi ve İdari Bilimler Dergisi, 14(1), 201-224.

Akyol, M., \& Demez, S. (2020). İnovasyonun Yüksek Teknoloji Ürün İhracati Üzerindeki Etkisi: Yeni Endüstrileşen Ülkeler İçin Panel Veri Analizi. Journal of Yaşar University, 15(57), 56-62.

Altıntaş, H., \& Mercan, M. (2015). Ar-ge harcamaları ve ekonomik büyüme ilişkisi: OECD ülkeleri üzerine yatay kesit bağımlılığı altında panel eşbütünleşme analizi. Ankara Üniversitesi SBF Dergisi, 70(2), 345-376.

Bojnec, Š., \& Fertő, I. (2011). Impacts of research and development on manufacturing trade. Zbornik radova Ekonomskog fakulteta u Rijeci: časopis za ekonomsku teoriju i praksu, 29(1), 65-88.

Braunerhjelm, P., \& Thulin, P. (2008). Can countries create comparative advantages? R\&D expenditures, high-tech exports and country size in 19 OECD countries, 1981-1999. International Economic Journal, 22(1), 95-111.

Cameron, A. C., \& Trivedi, P. K. (2009). Microeconometrics using stata (Vol. 5, p. 706). College Station, TX: Stata press.

Çetin, R. (2016). Yeni Sanayilesen Ülkelerde Ar-Ge Harcamaları ve Yüksek Teknoloji Ürünü İhracatı Arasındaki İliskinin Panel Veri Analizi Yöntemi İle İncelenmesi. Istanbul Üniversitesi Iktisat Fakültesi Mecmuasi, 66(2), 30.

Durgun, A., \& Çapik, E. (2018). Ar-Ge Harcamaları ve Yüksek Teknolojili Ürün İhracatının Büyümeye Etkisi: Türkiye Örneği. Yönetim Ve Ekonomi Araştırmaları Dergisi, 16(4), 301-314.

Dam, M. M., \& Bulut, Ş. (2015) Ar-Ge Yatırımlarının Dış Ticaret Performansına Etkisi: Oecd Ülkeleri İçin Ampirik Bir Analiz. EconAnadolu Conference, Eskişehir.

Demirtaş, G., \& Aktop, V. S. (2018). Türkiye'de Teknoloji Transferinin İçselleştirilmesi Üzerine Ampirik Bir Çalışma. Ekonomik Yaklaşım, 29(108), 69-103.

Dobrinsky, R. (2008). Innovation as a key driver of competitiveness. UNECE Annual Report Economic Essays, 6, 53-59.

Göçer, i. (2013). Ar-Ge harcamalarının yüksek teknolojili ürün ihracatı, dış ticaret dengesi ve ekonomik büyüme üzerindeki etkileri. Maliye Dergisi, 165(2), 215-240. 
Yaşar, M. (2020). The Relationship Between High-Tech Product Exports, R\&D Expenditures and Patent Applications: Dynamic Panel Data Analysis for Selected Countries, BILTURK, The Journal of Economics and Related Studies, 2(4), 557-571. doi: 10.47103/bilturk.791786

Gülmez, A., \& Yardımcıoğlu, F. (2012). OECD Ülkelerinde Ar-Ge Harcamaları ve Ekonomik Büyüme İlişkisi: Panel Eşbütünleşme ve Panel Nedensellik Analizi (19902010). Maliye Dergisi, 163(1), 335-353.

Güneş, S., \& Akın, T. (2019). Yüksek teknolojili ürün ïhracatı: Lider ülkeler ve Türkiye analizi. Sosyoekonomi Dergisi, 27(40), 11-29.

Halpern, L., \& Muraközy, B. (2012). Innovation, productivity and exports: the case of Hungary. Economics of Innovation and New Technology, 21(2), 151-173.

Han, Chirok, Peter CB Phillips, and Donggyu Sul. (2014). X-differencing and dynamic panel model estimation." Econometric Theory 201-251.

Kabaklarlı, E., \& Konya, S. (2019), OECD Ülkelerinde Yüksek Teknolojili Ürün İhracatının Ekonomik Büyümeye Etkisinin Panel Tahmini. Uluslararası Sosyal ve Beşeri Bilimler Araştırma Dergisi, 6(48), 4418-4426.

Kılıç, C., Bayar, Y., \& Özekicioğlu, H. (2014). Araştırma Geliştirme Harcamalarının Yüksek Teknoloji Ürün İhracatı Üzerindeki Etkisi: G-8 Ülkeleri İçin Bir Panel Veri Analizi. Erciyes Üniversitesi Iktisadi ve Idari Bilimler Fakültesi Dergisi, (44), 115130.

Kızılkaya, O., Sofuoğlu, E., \& Ay, A. (2017). Yüksek teknolojili ürün ihracatı üzerinde doğrudan yabancı sermaye yatırımları ve dışa açıklığın etkisi: Gelişmekte olan ülkelerde panel veri analizi. Doğuş Üniversitesi Dergisi, 18 (1), 63-78.

Labra, R., \& Torrecillas, C. (2018). Estimating dynamic Panel data. A practical approach to perform long panels. Revista Colombiana de Estadística, 41(1), 31-52.

Landesmann, M., \& Pfaffermayr, M. (1997). Technological competition and trade performance. Applied Economics, 29(2), 179-196.

Oğuz, S., \& Sökmen, A. G. (2020). Araştırma Geliştirme Harcamalarının Yüksek Teknolojili Ürün İhracatına Etkisi: OECD Ülkeleri Üzerine Bir Panel Veri Analizi. International Journal of Economic \& Administrative Studies, (27), 209-222.

Özer, M., \& Çiftçi, N. (2009). Ar-Ge tabanlı içsel büyüme modelleri ve Ar-Ge harcamalarının ekonomik büyüme üzerine etkisi: OECD ülkeleri panel veri analizi. Sosyal Ekonomik Araştırmalar Dergisi, Yıl 2009, Cilt 8, Sayı 16, 219 - 240.

Özçelik, Ö., Aslan, V., \& Özbek, R. İ. (2018). Ar-Ge Harcamalarıyla Yüksek Teknoloji İhracatı Arasındaki İlişki: Seçili 10 OECD Ülkesi İçin Panel Veri Analizi. Kastamonu Üniversitesi Iktisadi ve Idari Bilimler Fakültesi Dergisi, 20(3), 57-66.

Özkan, G., \& Yılmaz, H. (2017). Ar-Ge Harcamalarının Yüksek Teknoloji Ürün İhracatı ve Kişi Başı Gelir Üzerindeki Etkileri: 12 AB Ülkesi ve Türkiye İçin Uygulama (1996-2015). Bilgi Ekonomisi ve Yönetimi Dergisi, 12(1), 1-12.

Romer, P.M. (1989), What Determines the Rate of Growth and Technological Change? World Bank Working Paper, No. 279. 
Yaşar, M. (2020). The Relationship Between High-Tech Product Exports, R\&D Expenditures and Patent Applications: Dynamic Panel Data Analysis for Selected Countries, BILTURK, The Journal of Economics and Related Studies, 2(4), 557-571. doi: 10.47103/bilturk.791786

Ruiz-Porras, A. (2012). La investigación econométrica mediante paneles de datos: Historia, modelos y usos en México [Econometric research with panel data: History, models and uses in Mexico] (No. 42909). University Library of Munich, Germany.

Seçilmiş, N., \& Konu, A., Akar P.,G., (2019). Doğrudan Yabancı Yatırımların Ar-Ge

Faaliyetleri Üzerine Etkisi: Ampirik Bir İnceleme. Maliye Dergisi, Temmuz-Aralık 177, 28-39.

Şeker, A. (2019). Teknolojik Gelişme ve Yüksek Teknoloji İhracatının Ekonomik Karmaşıklık Endeksi Üzerindeki Etkisi: Türkiye Örneği. Yönetim ve Ekonomi: Celal Bayar Üniversitesi Iktisadi ve Idari Bilimler Fakültesi Dergisi, 26(2), 377-395.

Ünlükaplan, İ. (2009). Avrupa Birliği üyesi ülkelerde iktisadi kalkınma, rekabetçilik ve inovasyon ilişkilerinin kanonik korelasyon analizi ile belirlenmesi. Maliye Dergisi, 157, 235-250.

Yaşar, E. (2014). Çokuluslu Şirketler ve Doğrudan Yabancı Yatırımlar. 2. Baskı, Ankara: Hakan Basın Yayın Dağıtım.

Yıldırım, E., \& Kesikoğlu, F. (2012). Ar-Ge Harcamaları ille ìhracat Arasındaki Nedensellik ilişkileri: Türkiye Örneğinde Panel Nedensellik Testi Kanıtları. Marmara Üniversitesi Iktisadi ve Idari Bilimler Dergisi, 32(1), 165-180.

Zhang, K. H. (2007). Determinants of complex exports: Evidence from crosscountry data for 1985-1998. Economia Internazionale/International Economics, 60(1), 111-122. 